\title{
A 3D Visualization Approach for Process Training in Office Environments
}

Citation for published version (APA):

Aysolmaz, B., Brown, R., Bruza, P., \& Reijers, H. A. (2016). A 3D Visualization Approach for Process Training in Office Environments. In C. Debruyne (Ed.), OTM Confederated International Conferences "On the Move to Meaningful Internet Systems: On the Move to Meaningful Internet Systems: OTM 2016 Conferences (Vol. 10033, pp. 418-436). Springer. Lecture Notes in Computer Science No. 10033 https://doi.org/10.1007/978-3-319-48472-3_24

Document status and date:

Published: 18/10/2016

DOI:

10.1007/978-3-319-48472-3_24

Document Version:

Accepted author manuscript (Peer reviewed / editorial board version)

\section{Please check the document version of this publication:}

- A submitted manuscript is the version of the article upon submission and before peer-review. There can be important differences between the submitted version and the official published version of record.

People interested in the research are advised to contact the author for the final version of the publication, or visit the DOI to the publisher's website.

- The final author version and the galley proof are versions of the publication after peer review.

- The final published version features the final layout of the paper including the volume, issue and page numbers.

Link to publication

\footnotetext{
General rights rights.

- You may freely distribute the URL identifying the publication in the public portal. please follow below link for the End User Agreement:

www.umlib.nl/taverne-license

Take down policy

If you believe that this document breaches copyright please contact us at:

repository@maastrichtuniversity.nl

providing details and we will investigate your claim.
}

Copyright and moral rights for the publications made accessible in the public portal are retained by the authors and/or other copyright owners and it is a condition of accessing publications that users recognise and abide by the legal requirements associated with these

- Users may download and print one copy of any publication from the public portal for the purpose of private study or research.

- You may not further distribute the material or use it for any profit-making activity or commercial gain

If the publication is distributed under the terms of Article $25 \mathrm{fa}$ of the Dutch Copyright Act, indicated by the "Taverne" license above, 


\title{
A 3D Visualization Approach for Process Training in Office Environments
}

\author{
Banu Aysolmaz ${ }^{1}$, Ross Brown ${ }^{2}$, Peter Bruza ${ }^{2}$ and Hajo A. Reijers ${ }^{1}$ \\ 1 Vrije Universiteit Amsterdam, Business Informatics Group, the Netherlands - \\ b.e.aysolmaz@vu.nl, h.a.reijers@vu.nl \\ 2 Queensland University of Technology, Information Systems School, Australia - \\ r.brown@qut.edu.au, p.bruza@qut.edu.au
}

\begin{abstract}
Process participants need to learn how to perform in the context of their business processes. Process training is challenging due to cognitive difficulties in relating process model elements to real world concepts. In this paper we present a 3D Virtual World (VW) process training approach for office environments. In this VW, process participants can experience a process in an immersive environment. They interact with VW representations of process elements in changing locations, based on process activities. By means of embodied 3D representation, deep immersion and engagement in this environment, enhancements in long term memory learning and episodic memory usage for knowledge retrieval are expected. Our illustration of an example process model shows the applicability of the approach. We list a number of future directions to extend the use and the benefits.
\end{abstract}

Keywords: Process Training, Visual Metaphors, Human-centric BPM, Process Modeling, 3D Virtual Worlds

\section{Introduction}

Process participants, individuals that take part in the performance of processes, need to understand and learn those business processes to carry them out properly [21]. Business process models, or process models for short, are the most commonly used medium to communicate process knowledge to process participants [28]. A process model may cover a variety of perspectives including the activities performed, their flow, the roles involved and data objects used and produced [9]. As process models become complex by including more of these perspectives, learning the processes becomes more difficult for process participants [11]. Process training is essential to overcome this learning problem [10]. In addition, it is seen as one of the top issues in the process modeling field [18]. One of the main challenges, in particular, is the difficulty of mapping real world concepts to process model elements [7].

To solve this problem, few process training approaches use the embodiment of real life concepts and visual priming to stimulate the engagement of the process participants with processes. Examples are two-dimensional token simulation [16], 
storyboards using representative images [37, 20], physical artefact representation [19], and modeling with digital tabletop interfaces [31]. Though such approaches have their limitations and practical restrictions, they show the potential to enhance the engagement of process participants and increase memory recall of process details. Virtual worlds (VWs) can be utilized to overcome the problems of process training and provide a more practical, cost-effective and scalable training environment. VW approaches have proven to be successful in the process modeling field for eliciting process knowledge [14] and promoting collaboration [35]. Two capabilities of VWs can particularly help to enhance process training: (1) deep immersion of process participants by an embodied 3D representation of the process environment, and (2) heavy engagement of process participants via interacting with process concepts in the VW. By realizing these capabilities in a VW process training environment, process participants may store expertise in Long Term Memory (LTM) and in this way retrieve contextual process knowledge from highly efficient episodic experiential memories.

The design of a VW is shaped by the real-life environment where a process takes place. Processes may be categorized as information and material processes. Material processes are performed using physical objects and artifacts (e.g. hospital, manufacturing environments). On the other hand, information processes are mostly performed in office environments, where the information work is conducted using digital artifacts [27]. In contemporary organizations, there is a significant shift to information processes in every domain [25]. A lot of organizations now solely perform information processes; such as software development companies and governmental organizations. Many others implement a high number of information processes although their core processes are material processes. Therefore, organizations need to train their process participants -i.e. employees, citizens, service users- for their information processes. In this paper, we focus our approach on information processes, or office environments. Our general approach assumes an extant model developed by other means; we are not describing a method to perform process modeling in virtual reality, as this is covered elsewhere [6]. Instead, our VR visualization approach ingests an annotated process model, allowing it to represent, in 3D, information flow elements.

In this paper, we propose a $3 \mathrm{D}$ visualization approach for process training in an office VW configured for process activities. We define a list of activity patterns to categorize the activities in office environments and use them to configure the VW. In this way, different activity types are distinguishably presented in the VW. We use a human centric third person view to visualize the location where the activity takes place, its process elements and their interactions. A complete process experience is ensured by transitioning from one activity to another through VW interactions. Our approach provides an embodied representation of the users' own workspace together with process concepts assembled into the VW. We show the applicability of our approach on an example process model by using mockups. Due to the promising research showing the efficacy of such VW environments in enhancing recall $[14,34]$, we believe that the use of our approach may improve process training via increasing the ability of workers 
to recall process details, leading to greater productivity. Furthermore, such VWbased process training should prove to be more engaging than standard training methods, leading to an increase in the uptake of process training by workers.

The structure of the paper is as follows. In Section 2, we describe our VW process training approach including the visualization components, activity pattern definitions, design decisions and lastly the steps taken for process training. We depict the application of our approach via mockups using an example process model in Section 3. We present the related work on process training in VWs and describe the derivation of activity patterns based on the literature in Section 4 . Lastly, we conclude the paper and present the future work in Section 5.

\section{Visualization Approach Design}

In this section we describe the design details of our approach. First, we describe the components of the approach. Then, we provide the activity pattern definitions used for the configuration of the VW. We discuss the underlying design decisions for the VW. Lastly, we describe the steps taken in the VW to train a process participant on a specific process instance.

Organizations need to provide training for their stakeholders, such as the employees of a company or the users of organizational services. A pivotal issue in this regard is the effect of the training on human Long Term Memory (LTM); if those subjected to training can effectively recall the required information depending on the context. There is an established view that domain experts store expertise in LTM using knowledge structures in the form of schema. In addition, experts exhibit superior retrieval from episodic memory than non-experts for domain typical information [23]. This is largely because they can access LTM to rapidly and reliably encode and retrieve the information, rather than maintaining it in Short Term Memory (STM) alone. Access to episodic memory is important for retrieving information in context. Basically, access to episodes coded in memory similar to the current task, allow relevant information to be retrieved to promote effectiveness in the task at hand. The question arises whether immersive environments can enhance episodic memory. If so, these environments would offer the potential for those being trained to more effectively access their expertise in LTM for deployment after training. However, there have been few studies aimed at assessing the performance of VWs and Virtual Reality (VR) on episodic memory. Those studies that have been conducted on assessing the effect of VR on human memory give rise for cautious optimism [34, 14]. Thus we wish to develop a method that keys into the situated LTM memory of process participants. In particular, we wish to design a visualization approach that will allow people to relate the semantic knowledge of process models with contextualized representations of standard offices, thus enabling the viewer to relate the process model concepts to familiar desk elements in their workplace that they remember via their LTM. 


\subsection{Visualization Components}

Figure 1 shows the components of our approach and how those components are implemented. Drawing from task-oriented visualization approaches, such as [36], we base our visuals on the information representing the state of process logic; in this case the activity patterns. The related visualization task involves users understanding the process elements being used in executing an activity -the input/output data objects, roles and the systems used-and control-flow aspects such as choices, via visual representations. The Design Decisions in Section 2.3 , based on the literature, have been used to fulfill this task by creating a configuration pipeline, which we now describe.

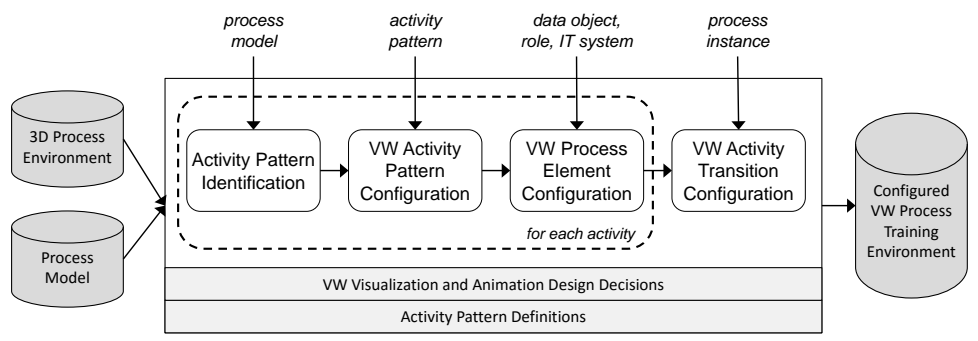

Fig. 1: Approach components.

The approach takes as input a previously generated " $3 D$ Process Environment" and the "Process Model" which defines the process to be trained. The process instance for which the training will be provided must be specified in this process model. To apply the approach, we first handle each activity in the selected instance of the input process model. First, the pattern of the activity is identified based on the "activity pattern definitions". The VW is configured for the activity at hand based on its pattern. More specifically, the virtual environment where the activity takes place is designed based on the action type (i.e. personal, decision, group, data transfer, delegation); and the interactions to take place in the VW based on the related process elements (i.e. data objects, roles, IT systems). Then, $V W$ process elements are configured by placing the representations of the related process elements for the activity in the VW based on the previous step. That is, for example, a representation of an input data object with its label is placed in the activity's VW environment as configured before. The VW is lastly configured for visualization of the transitions between the activities in the selected process instance. During the VW configuration, underlying "VW visualization and animation design decisions" are utilized to enable the trainee to relate process model concepts to their own environment.

Having a configurable approach facilitates progression, as required in training scenarios. Such configurations provide a powerful generic basis for the representation of a large number of information process models by virtue of the generalized 
3D environment (office) and the utilization of the generalized activity patterns. In the next section, we introduce those activity patterns.

\subsection{Activity Pattern Definitions}

In this section, we explain our approach to categorize the process activities as patterns and present the list of activity pattern definitions. Then, we explain how we identify the pattern an activity belongs to, i.e. using its action category, relations with other process elements and verb phrases used in the action.

Activities are the building blocks of process models [29]. They specify the actions performed in the process model. Model readers comprehend the process models based on the activity type [24]. In one dimension, the inherent nature of an action indicated by the activity's textual label impacts how the model readers understand the process [29]. On the other dimension, the activities in a process model are characterized by the process elements related to them [21]. For example, if a data object is connected to an activity as an output, this means that such an output is created as the activity is performed.

Table 1 shows the activity patterns we identified for information processes. We developed this categorization based on the two dimensions of an activity; i.e. the action and the element relations. Category and sub-category columns in Table 1 show the patterns grouped on the action dimension. The last four columns display the possible relations for an activity pattern. We distinguish the patterns under each sub-category by a different combination of relations with roles, inputs and outputs. Below, we further describe the rationale for using these dimensions.

Action type: Activities can be classified based on the inherent nature of the action specified in the label as the verb phrase [38]. As an example, "prepare problem report" is an activity label and "prepare" is the verb phrase, thus the action in this activity. As seen in Table 1, activities can be mainly categorized for being performed individually or in a collaborative setting [7]. Then they are sub-categorized. An individual activity may either be a personal activity, or a decision activity, which is followed by alternative outcomes. Collaborative activities can be categorized as group activities performed by multiple roles, data transfer and delegation activities [7].

Process element relations: Activities in a given sub-category can further be distinguished based on their relations with other process elements. Such relations are shown as elements connected to the activity in process models or as mentioned in the activity label. More specifically, the following process elements can be related to an activity: (1) the IT systems on which the activity is performed, (2) the roles involved in the activity, and (3) the data objects as inputs or outputs. Each pattern under a sub-category has a different possible combination of related process elements.

Based on these two dimensions, we define an "activity pattern" as a recurrent business function to fulfill a certain type of action in an office environment and based on the action, display a set of relations with data objects, roles and IT systems. The last four columns in Table 1 display the relations with other process 
Table 1: Activity pattern list

\begin{tabular}{|c|c|c|c|c|c|c|}
\hline No Category & $\begin{array}{c}\text { Sub- } \\
\text { category }\end{array}$ & Pattern & $\begin{array}{c}\text { IT } \\
\text { System }\end{array}$ & Role & Input & Output \\
\hline \multirow{5}{*}{ Individual } & \multirow{3}{*}{ Personal } & Prepare & $\mathrm{O}$ & - & $\mathrm{O}$ & $\mathrm{X}$ \\
\hline & & Examine & $\mathrm{O}$ & - & $\mathrm{X}$ & - \\
\hline & & Perform & $\mathrm{O}$ & - & - & - \\
\hline & \multirow{2}{*}{ Decision } & Approve & $\mathrm{O}$ & - & - & - \\
\hline & & Evaluate & $\mathrm{O}$ & - & $\mathrm{X}$ & $\mathrm{O}$ \\
\hline \multirow{7}{*}{ Collaboration } & \multirow{2}{*}{ Group } & Meet & $\mathrm{O}$ & $\mathrm{I} / \mathrm{X}$ & $\mathrm{O}$ & - \\
\hline & & Work mutually & $\mathrm{O}$ & I & $\mathrm{O}$ & $\mathrm{X}$ \\
\hline & \multirow{4}{*}{ Data transfer } & Request info & $\mathrm{O}$ & I & - & - \\
\hline & & Inform & $\mathrm{O}$ & I & - & I \\
\hline & & Receive & $\mathrm{O}$ & I & $\mathrm{X}$ & - \\
\hline & & Send & $\mathrm{O}$ & I & - & $\mathrm{X}$ \\
\hline & Delegation & Assign task & $\mathrm{O}$ & I & $\mathrm{O}$ & $\mathrm{O}$ \\
\hline
\end{tabular}

elements relevant for an activity pattern. The column Role is marked with an "X" or "I" if a role other than the performer is involved in the activity. Such kind of patterns represent namely collaborative [26] or group [7] type of activities. For individual activity patterns, there is no related role other than the performer of the activity, which is indicated by a "-". In only one pattern, meet, involvement of roles may be depicted explicitly in the process model (indicated with an "X"). At other times, the implicit inclusion of another role is indicated through the activity label such as "Define project plan with contract manager". Such an implicit relation to a role is indicated with an "I". The columns input and output in Table 1 show the possible data object relations for an activity. For example, for the activities of type prepare pattern, an input data object may or may not exist (indicated with "O" to show optionality) but an output data object should always take place (indicated with an "X"). For the "inform" pattern, the output is implicit as there is a hidden output in the form of information. The use of an IT system in a process model is optional for all patterns. Although an activitysystem is not a distinguishing relation for the patterns, we show it to make the relation visible.

In Section 4, we explain the existing literature we used to derive the activity patterns. We evaluated the suitability of the activity patterns on two example process model sets. Namely, we used (1) project management processes of a company containing 37 activities, and (2) requirements management processes of another company containing 54 activities. We mapped each activity label to the related pattern to ensure all activities correspond to a pattern.

Pattern identification for an activity: To configure the VW for a specific process, we identify the pattern each activity belongs to. We first determine in which category and sub-category the activity falls into based on the action in its label. Then, we look into the process elements the activity is related to. The pattern is identified based on the matching relation set in Table 1. For example, we look into the activity named "update problem definition" in Figure 4. We first 
identify that it is in "personal" sub-category. Then we observe that the activity has an output, which indicates that it is of "prepare" pattern. The verbs in the activity label indicating the action type provide us a hint to easily identify the pattern an activity falls into. There may be a variety of verbs used to indicate an activity in a specific pattern [29]. We gathered the exemplary verbs found in activity labels from the literature, WordNet synonyms and exemplary process models. We provide here the example verbs for three patterns:

- "Prepare" pattern: "complete, create, make, define, specify, develop, update, modify, change, finish, implement, and close".

- "Request info" pattern: "communicate, ask question, and consult".

- "Delegate" pattern: "hand out, appoint, and designate".

\subsection{VW Visualization and Animation Design Decisions}

The design decisions made in our visualization approach are described below, with related literature, to describe the reasoning in our visualization designs.

Information Process Environment - as previously mentioned, information processes are heavily office based [27]. Therefore, we present the process model concepts within a generic 3D office environment. The intention of this office representation is to train people in process concepts, and specifically, mapping the concepts to real-life execution. The intention is not to provide an operationally detailed interactive system, but to present information focused on the transitioning of process activities, data objects, roles and certain control perspective elements. Thus, the interactions in the environment focus on the process activities, not detailed animations of all artifacts in the office. We assume a single instance of the process is executing in the VW office.

Location-based Activities - process activities are placed within an office in discrete locations, such as desks and meeting rooms. Locational memory is shown to be an effective method for remembering abstract lists [3] due to the contextual elements present at each location, and the embodied cognition involved in remembering locations (viz. using your body to compute locations and dimensions) [22].

Third Person View - in our approach, the user views the other avatars within the environment to observe their tasks. For this, we utilize what is known as a third person viewpoint, as it has been shown to work well for training scenarios. In this way, users are able to understand their tasks by subjectively observing someone perform the tasks [4].

Human Resource Centric - our view is focused on the tasks performed by humans as activity patterns [7], thus each view has an avatar representing a role within the resource perspective of a process model. The organizational element or swimlane constructs in process modeling notations are mapped directly to a resource role representation, shown by a role-labeled model of a person.

Process Element Visuals - we need to design appropriate activity annotations to visualize the transition steps in the execution of an activity in a process model. Visualization design frameworks [36] direct the development of user task-oriented visuals. We do not seek to show people performing the work 
physically, as the work is mostly performed at a desktop or laptop computer. The visualization elements are icons for providing insight into the execution of the process model. Specifically, our visualization approach provides visual support for insight into the control, data and resource perspectives of the underlying information process.

Interaction Basis - since the visualization is focused on the control flow order, human and non-human resources and the data perspective, there are no other interactions or detailed IT system interfaces required. Actions are reduced to simple clicks centered on the activity to be executed for purposes of generality (easy to configure from a file), multiple media implementations (such interactions are appropriate for mobile VR headsets), simplicity in training (low barrier to entry for interaction complexity) and lastly, mapping well to the theoretical underlying models with transitions occurring as a generalized workflow model. That is, tasks are performed in a sequence, and choices are made by an actor within an organization.

\subsection{Process Training Steps}

We now present the details of how a process participant uses the process visualization approach to receive training for a process. The generic interaction scheme is presented in Figure $2^{1}$. This scheme is configured to represent all activity patterns. For each pattern the input data objects and the role(s) that provide data appear on the upper left, the systems used in the upper middle and the output data objects, the role(s) to whom data is provided or a task is delegated on the right, with each element appearing after a single click on the activity. When a choice needs to be made, a dialog box is shown in the VW in front of the role with the annotated arcs being represented on the dialog. In our visualization approach, the dialog is shown, but the path is chosen by the process instance, highlighting it in a different color, as shown in Figure $3^{1}$.

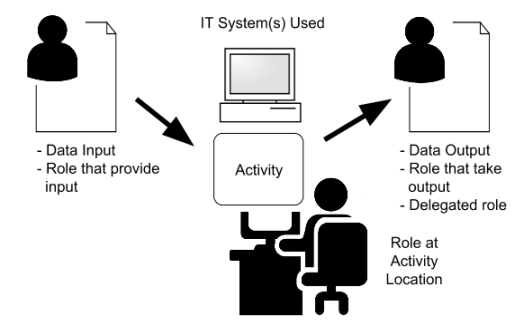

Fig. 2: General approach to visualizing activity patterns.

\footnotetext{
${ }^{1}$ Computer and Man Icon - Designed by Freepik and distributed by Flaticon http://www.flaticon.com/
} 


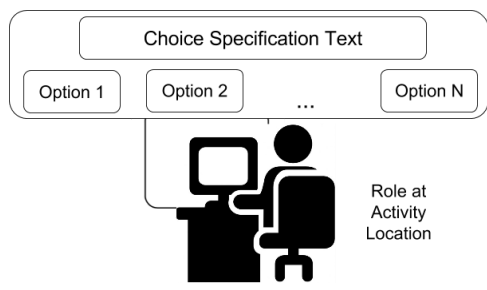

Fig. 3: General approach to visualizing choice for decision patterns.

Utilizing the above visual structures, the activities and transitions between them are interactively visualized with the following steps, each enacted by clicking on the activity box (see https://youtu.be/h6ZKACo9xxE for example video):

1. Present activity is shown in front of a role in red for an available activity with traffic light metaphor [5];

2. Clicking on the activity commences it, turning it amber to represent "in progress";

3. Input data objects and/or roles from which data is obtained for an activity appear to the left as a labeled icon, with an arrow pointing right;

4. Systems used in the activity are shown in the middle;

5. Output data objects and/or roles to which data is provided or a task is delegated by the activity appear to the right as a labeled icon, with an arrow pointing to it;

6. Activity changes color to green to indicate its successful completion;

7. If the activity is a Decision pattern, then a choice dialog box appears in front of the role.

8. Final clicking on the activity automatically transitions the user to the next role location for the next activity; this may be the same location if the next task is performed at the present location by the same role.

In the next section, we illustrate the application of our approach on an example process.

\section{Example Application}

In this section, as a form of validation by example, we show the application of our generic visualization approach to an example process model. We argue that we can show nearly every configuration of an office process model by using activity-pattern based representation within a 3D VW.

Our example process model shown in Figure 4is about resolution of problems in an organization for a corporate IT system, with three roles (namely the Requestor, Support and the Developer). In this model, we utilize Business Process Model and Notation (BPMN) symbols ${ }^{2}$ to illustrate our example. Many other notations and modeling styles are found in practice for control-flow based pro-

${ }^{2}$ http://www.omg.org/spec/BPMN/2.0/ 
cess modeling. Our VW visualization approach based on the activity patterns is applicable in the same way for other available notations.

The example process from Figure 4 is triggered when a problem is identified for the corporate system. The first activity is to prepare a problem report by the Requestor role on the Ticket Management System. Once the initial problem report is created as the output data object, the Support role evaluates the problem definition using this report. The result of the evaluation may lead to three alternative flows. If the problem cannot be identified, the Support requests more information on the problem. If the problem is not relevant, the Support defines the problem rejection reason on the Ticket Management System, then informs the Requestor on the problem rejection and the process is finalized. If the problem is accepted, the Support assigns a developer to resolve the problem by using the resource plan. Then, the rest of the activities are executed until the problem is resolved. Below we present our VW visualization approach for the process instance highlighted in red in Figure 4.

For each pattern we provide the name of the base pattern, and then show how the base visualization is configured for the underlying pattern, including the visuals and the interaction steps. Three roles from the process model have been instantiated within the departments; they are shown at three different desks to motivate the user to move around the space. The following examples specifically illustrate the patterns 1, 5, 7, 11 and 12, listed in Table 1 . An example is provided for each sub-category, viz. personal, decision, group, data transfer and delegation, giving an informative explanation of all the visualization concepts needed for the patterns. Start and end nodes are removed for clarity. Repetitions of similar patterns within the instance are also suppressed in detail for clarity. We now exemplify the use of the process visualization approach on the process instance marked in red on Figure 4. For the selected activities, we list the interaction steps performed by clicking on the activity box and provide visualization examples from the configured VW.

Activity 1. "Prepare Problem Report" (prepare pattern in personal subcategory) (see Figure 5):

1. Show input(s) - None;

2. Show system - Ticket Management System;

3. Show output(s) - problem report [initial].

Activity 2. "Evaluate Problem Definition" (evaluate pattern in decision sub-category) (see Figure 6):

1. Show input(s) - problem report [initial];

2. Show system - None;

3. Show output(s) - None;

4. Show the choices following the activity.

Activity 3. "Assign Developer for Problem Resolution" (assign task pattern in delegation sub-category) (see Figure 7):

1. Show input(s) - Resource Plan;

2. Show system - None;

3. Show output(s) - None; 




Fig. 4: Example problem resolution process model 


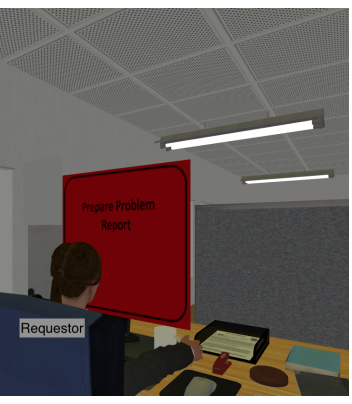

(a) 1. Initiated.

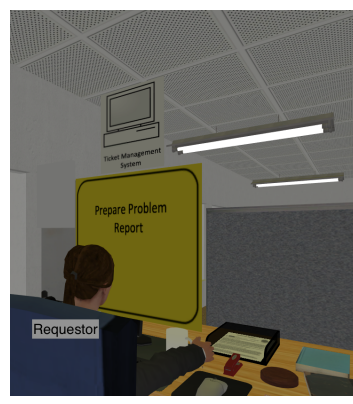

(b) 2. Commenced.

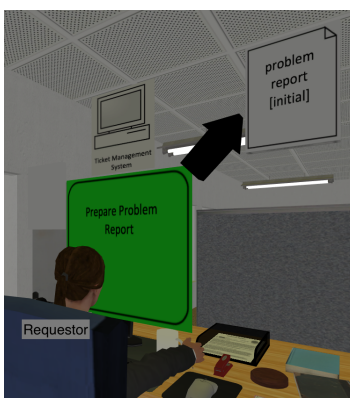

(c) 3. Finalized.

Fig. 5: Prepare pattern example images for each step showing an output document created using an information system.

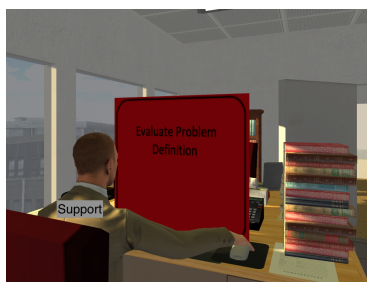

(a) 1. Initiated.

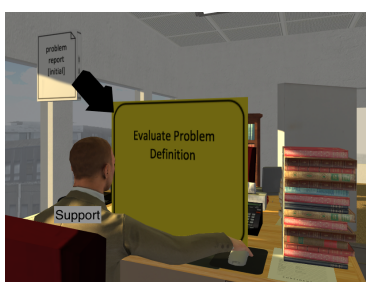

(b) 2. Commenced.

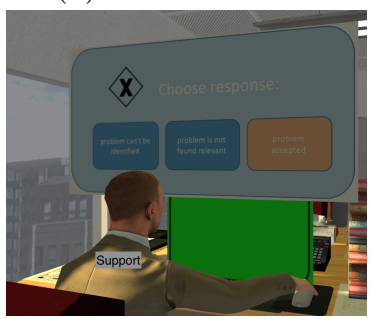

(d) 4. Choice.

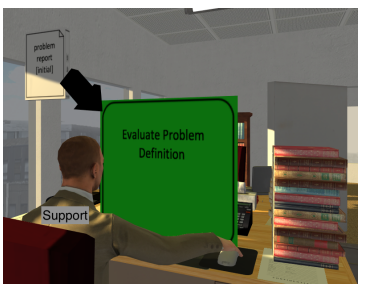

(c) 3. Finalized.

Fig. 6: Evaluate pattern example images for each step with a choice dialog.

4. Show the delegated role - Developer Role.

Activity 4. "Perform Root Cause Analysis" (perform pattern in personal sub-category) with no visible inputs or outputs.

Activity 5. "Define Problem Resolution Plan with Support" (work mutually pattern in group sub-category) (see Figure 8):

1. Show input(s) - None;

2. Show system - None;

3. Show output(s) - Problem resolution plan [final]; 


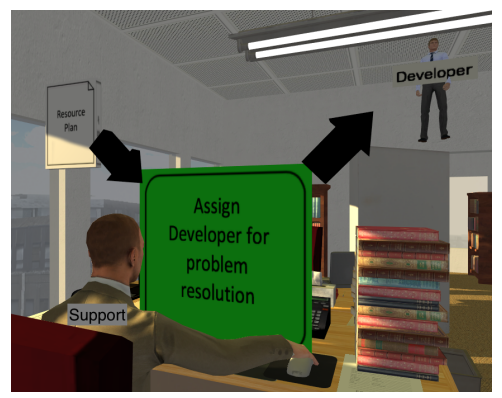

Fig. 7: Assign pattern example image for the last step.

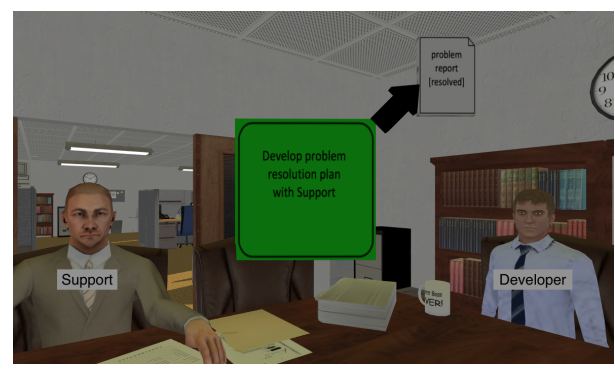

Fig. 8: Work mutually pattern example image for the last step.

Activity 6. "Implement Problem Resolution" (prepare pattern in personal sub-category) with input problem resolution plan [final], using Corporate IT System and output problem report [implemented].

Activity 7. "Report Support on Problem Resolution" (send pattern in data transfer category) (see Figure 9):

1. Show system - None;

2. Show output(s) - problem report [resolved];

3. Show the role the data object is sent to - Support.

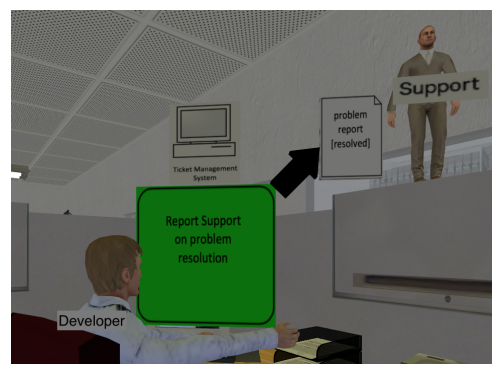

Fig. 9: Send pattern example image for the last step. 
Activity 8. "Verify Problem Resolution" (evaluate pattern in decision subcategory) with the input problem resolution plan [final] and no output, followed by a choice dialog.

Activity 9. "Report Requestor on Verified Problem Resolution" (send pattern in data transfer sub-category) with the output problem report [verified] and the Requestor role the data object is sent to.

Activity 10. "Approve problem resolution" (approve pattern in decision subcategory) with the input problem report [verified], using the Ticket Management System, followed by a choice dialog.

Activity 11. "Close Problem" (prepare pattern in personal sub-category) with the input None, using the Ticket Management System and producing the outputs Problem Report [closed] and Corporate Problem List.

\section{Related Work}

In this section, we first introduce the prominent work we used on VW process training and provide a comparison with relevant solutions. We then introduce the pattern-based approaches in process modeling and explain how we derived the activity patterns based on the literature.

\subsection{Process Training in VWs}

This research builds on the pioneering work performed using VWs to solve modeling, simulation and elicitation problems in process management field $[6,32,13$, $7,14]$. However, this paper is one of first to proceed in the direction of using $3 \mathrm{D}$ VWs and VR to train people in information process model concepts via a generic and configurable 3D VW visualization approach. Most research in 3D VWs focuses on simulating operational physical tasks in 3D environments [39]. Closer to our work, other 3D VW process research work involves the use of process software systems, such as BPML, to assist in training physically based applications (e.g. healthcare) [8]. These systems do not emphasize informational flows as part of the training as done in this paper.

Amongst industry process simulation systems [17], the closest to our work is OnMap (www.onmap.com), a 2.5D world system for visualizing business processes. However, in comparison to OnMap, we have formalised process representations more clearly from a theoretical pattern basis, improving the mapping between the defined process perspectives. In addition, we offer the concept and option of using immersive VR to enhance training in information process knowledge by improving LTM recall.

\subsection{Patterns in Process Modeling}

Patterns have been applied to define recurrent solutions to frequent problems in the process modeling field, and ever-increasing usage is expected [15]. A review of collaborative work reveals the variety of pattern usage [41]. The pattern concept 
Table 2: Work utilized on defining activity patterns

\begin{tabular}{lll}
\hline $\begin{array}{l}\text { Pattern } \\
\text { Category }\end{array}$ & $\begin{array}{l}\text { Pattern Sub- } \\
\text { category }\end{array}$ & Related Work \\
\hline \multirow{3}{*}{ Individual } & Personal & $\begin{array}{l}\text { Mendling et al. [29], Fleischmann et al. [12], } \\
\text { Brown et al. [7] }\end{array}$ \\
\cline { 2 - 3 } & Decision & Thom et al. [40], Brown et al. [7] \\
\hline \multirow{5}{*}{ Collaboration } & Group & Lonchamp [26] \\
\cline { 2 - 3 } & Data transfer & $\begin{array}{l}\text { Thom et al. [40], Mendling et al. [29], } \\
\text { Brown et al. [7], Fleischmann et al. [12] }\end{array}$ \\
\cline { 2 - 3 } & Delegation & $\begin{array}{l}\text { Brown et al. [7], Lonchamp [26], } \\
\text { van der Aalst et al. [2] }\end{array}$ \\
\hline
\end{tabular}

is most heavily used in the definition of workflow patterns [1]. They proved to be helpful in a VW study where the purpose was to visualize the assignment of resources to workflow tasks [13]. However, they characterize how the systems work, rather than how the humans perform the processes. Other studies define patterns for a collection of activities rather than individual activities; i.e. for identifying reusable activity sets or specifying good practices [30,40].

We harnessed knowledge from the literature to identify the activity categories and define the patterns. Table 2 summarizes the work we used for each pattern type. We first categorized the patterns as individual and collaboration [41]. We then further sub-categorized them based on the type of the action performed $[7,29,38]$. We used the verb categorization of Mendling et al. obtained by a synonym-analysis of the well-known SAP and MIT Process Handbook reference models using WordNet [29] . We then incorporated the rest of the patterns based on other works such as collaborative work patterns [26], and micro workflow patterns $[40,1]$.

\section{Conclusion/Future Work}

In this paper, we introduced an approach for training process participants in VWs to overcome the difficulties of process learning in office environments. We namely address the problem of mapping real world concepts to process model elements. In this approach, 3D VWs are used to visualize the office environments where information processes are performed. The approach includes the design of a dynamic training environment in which process participants interact with the process model elements represented as VW artifacts. We use the concept of activity patterns to categorize the activities in process models. The design of the VW training environment and the interaction of the process participant with the VW elements are based on these patterns. We used the approach of validation by example to show the applicability of this training environment for a problem resolution process model.

The contribution of this paper is the introduction of a visualization approach for developing a VW process training environment that can provide significant benefits in process learning. A deep immersion of the process participants into 
the represented processes is enabled by means of the embodied 3D representation of their workspace. Moreover, the interaction features may heavily enhance engagement with the process concepts. Both factors promote the learning experience to be stored in LTM and process knowledge to be reused efficiently from episodic memory.

Potential limitations of this work arise from the lack of experimental research to validate the expected benefits with real process participants. The next planned step of this work is the development of a VW process training application supporting our approach and evaluating the effect of the approach on process learning. In addition, we foresee various potential extensions to widen the usability of the approach. We plan to follow the "crawl-walk-run" approach to design a progressive training schema [33]. Our current design presents the "crawl" level where the VW is fully configured. This can be extended to more advanced training by reducing help and requiring more recall of the work. To support those levels and enhance the user experience, other views are to be added to the VW. For example, an orthographic overview is needed for the user to manually "go" from one location to the other in the VW. Such a view also facilitates the ability to visualize parallelism, which is presently absent in our approach. A dynamic process model view may be integrated to enhance the understanding of process model notation constructs. Potential extensions are planned on the inclusion of automated activities that do not involve humans and support for information processes other than office workspaces (such as outdoor mobile spaces).

Other improvements are to be supported with technological advancements. Virtual Reality (VR) devices have been shown to significantly enhance user immersion, which is easy to implement in our approach specifically as a "crawl" level. Another long term plan is the use of $3 \mathrm{D}$ scanning camera solutions to easily digitize the process participants' own workspace and provide the highest level of reality. Moreover, the identification of the activity patterns for a process model may be automated by using Wordnet's synonym sets, implementing a self-learning mechanism and analyzing element relations in the process model.

\section{Acknowledgement}

This project has received funding from the European Union's Horizon 2020 research and innovation programme under the Marie Skłodowska-Curie grant agreement No 660646.

\section{References}

1. van der Aalst, W.M.P., ter Hofstede, A.H.M., Kiepuszewski, B., Barros, A.P.: Workflow Patterns. Distrib. Parallel Databases 14(1), 5-51 (2003)

2. van der Aalst, W.M., Song, M.: Mining Social Networks: Uncovering Interaction Patterns in Business Processes. In: Int. Conf. Bus. Process Manag. (BPM 2004). Lecture Notes in Computer Science, vol. 3080, pp. 244-260. Springer-Verlag, Berlin (2004) 
3. Baddeley, A., Eysenck, M., Anderson, M.: Memory. Taylor \& Francis (2015)

4. Bailenson, J., Patel, K., Nielsen, A., Bajscy, R., Jung, S.H., Kurillo, G.: The effect of interactivity on learning physical actions in virtual reality. Media Psychology 11(3), 354-376 (2008)

5. Brown, R., Paik, H.y.: Multi-faceted Visualisation of Worklists, pp. 153-178. Springer Berlin Heidelberg, Berlin, Heidelberg (2009)

6. Brown, R., Recker, J., West, S.: Using virtual worlds for collaborative business process modeling. Business Process Management Journal 17(3), 546-564 (2011)

7. Brown, R., Rinderle-Ma, S., Kriglstein, S., Kabicher-Fuchs, S.: Augmenting and Assisting Model Elicitation Tasks with 3D Virtual World Context Metadata. In: Meersman, R., Panetto, H., Dillon, T., Missikoff, M., Liu, L., Pastor, O., Cuzzocrea, A., Sellis, T. (eds.) Move to Meaningful Internet Syst. OTM 2014 Conf. SE - 3, Lecture Notes in Computer Science, vol. 8841, pp. 39-56. Springer Berlin Heidelberg (2014)

8. Chodos, D., Stroulia, E., Boechler, P., King, S., Kuras, P., Carbonaro, M., de Jong, E.: Healthcare education with virtual-world simulations. In: Proceedings of the 2010 ICSE Workshop on Software Engineering in Health Care. pp. 89-99. SEHC '10, ACM, New York, NY, USA (2010)

9. Curtis, B., Kellner, M.I., Over, J.: Process Modeling. Commun. ACM 35(9), 75-90 (1992)

10. Dumas, M., La Rosa, M., Mendling, J., Reijers, H.A.: Fundamentals of business process management. Springer (2013)

11. Faltin, N., Von Rosing, M., Scheer, A.W.: Real-time learning: Business process guidance at the point of need, vol. 1. Elsevier Inc. (2014)

12. Fleischmann, A., Schmidt, W., Stary, C., Obermeier, S., Börger, E.: Subjectoriented business process management. Springer Berlin Heidelberg (2012)

13. Guo, H., Brown, R., Rasmussen, R.: Workflow Resource Pattern Modelling and Visualization. Proc. Thirty-Sixth Australas. Comput. Sci. Conf. - Vol. 135 pp. 31-40 (2013)

14. Harman, J., Brown, R., Johnson, D., Rinderle-Ma, S., Kannengiesser, U.: Augmenting process elicitation with visual priming: An empirical exploration of user behaviour and modelling outcomes. Inf. Syst. (feb 2016)

15. Harmon, P.: Business Process Change. Morgan Kaufmann (2014)

16. Holzmüller-Laue, S., Schubert, P., Göde, B., Thurow, K.: Visual Simulation for the BPM-Based Process Automation, pp. 48-62. Springer Berlin Heidelberg, Berlin, Heidelberg (2013)

17. Huang, B., Tang, H.j.: Study of Workshop Production System Based on Petri Nets and Flexsim, pp. 833-844. Atlantis Press, Paris (2016)

18. Indulska, M., Recker, J., Rosemann, M., Green, P.: Business Process Modeling: Current Issues and Future Challenges, pp. 501-514. Springer Berlin Heidelberg, Berlin, Heidelberg (2009)

19. Jonathan, E., Grosskopf, A., Weske, M., Leifer, L.: Tangible Business Approach Process Modeling: A New Approach. In: Int. Conf. Eng. Des. ICED. pp. 485-494. No. August, Stanford (2009)

20. Kathleen, N., Ross, B., Kriglstein, S.: Storyboard augmentation of process model grammars for stakeholder communication. In: Proceedings of the 5th International Conference on Information Visualization Theory and Applications (VISIGRAPP 2014). pp. 114-121 (2014)

21. Kellner, M.I., Becker-kornstaedt, U., Riddle, W.E., Tomal, J., Verlage, M.: Process Guides : Effective Guidance for Process Participants. In: Proc. Fifth Int. Conf. 
Softw. Process. pp. 14-17. No. June, The International Software Process Association Press (1998)

22. Kühn, S., Werner, A., Lindenberger, U., Verrel, J.: Acute immobilisation facilitates premotor preparatory activity for the non-restrained hand when facing grasp affordances. NeuroImage 92, $69-73$ (2014)

23. Kimball, D.R., Holyoak, K.J.: Transfer and expertise. The Oxford handbook of memory pp. 109-122 (2000)

24. Leopold, H., Smirnov, S., Mendling, J.: On the refactoring of activity labels in business process models. Inf. Syst. 37(5), 443-459 (2012)

25. Lindsay, A., Downs, D., Lunn, K.: Business processes - Attempts to find a definition. In: Inf. Softw. Technol. vol. 45, pp. 1015-1019 (2003)

26. Lonchamp, J.: Process model patterns for collaborative work. In: Proc. 15th IFIP World Comput. ... (1998)

27. Medina-Mores, R., Winograd, T., Flores, R., Flores, F.: The Action Workflow Approach to Workflow Management Technology. In: Proc. 1992 ACM Conf. Comput. Coop. Work. pp. 281-288 (1992)

28. Melcher, J., Mendling, J., Reijers, H.A., Seese, D.: On Measuring the Understandability of Process Models. In: Rinderle-Ma, S., Sadiq, S., Leymann, F. (eds.) Bus. Process Manag. Work. SE - 44, Lecture Notes in Business Information Processing, vol. 43, pp. 465-476. Springer Berlin Heidelberg (2010)

29. Mendling, J., Recker, J., Reijers, H.A.: On the usage of labels and icons in business process modeling. Int. J. Inf. Syst. Model. Des. 1(2), 40-58 (2010)

30. Moody, P., Gruen, D., Muller, M.J., Tang, J., Moran, T.P.: Business activity patterns: A new model for collaborative business applications. IBM Syst. J. 45(4), 683-694 (2006)

31. Oppl, S., Stary, C.: Effects of a Tabletop Interface on the Co-construction of Concept Maps, pp. 443-460. Springer Berlin Heidelberg, Berlin, Heidelberg (2011)

32. Poppe, E., Brown, R., Recker, J., Johnson, D.: Improving remote collaborative process modelling using embodiment in $3 \mathrm{~d}$ virtual environments. In: Proceedings of the Ninth Asia-Pacific Conference on Conceptual Modelling - Volume 143. pp. 51-60. APCCM 2013, Australian Computer Society, Inc., Darlinghurst, Australia (2013)

33. Redkar, S.: Teaching Advanced Vehicle Dynamics Using a Project Based Learning ( PBL ) Approach. J. STEM Educ. Innov. Res. 13(3), 17-30 (2012)

34. Sauzéon, H., Arvind Pala, P., Larrue, F., Wallet, G., Déjos, M., Zheng, X., Guitton, P., N'Kaoua, B.: The use of virtual reality for episodic memory assessment: Effects of active navigation. Experimental Psychology 59(2), 99 - 108 (2012)

35. Schmeil, A., Eppler, M.J.: Formalizing and promoting collaboration in 3D virtual environments - A blueprint for the creation of group interaction patterns. In: Lect. Notes Inst. Comput. Sci. Soc. Telecommun. Eng., vol. 33 LNICST, pp. 121-134. Springer Berlin Heidelberg (2010)

36. Sedlmair, M., Meyer, M., Munzner, T.: Design Study Methodology: Reflections from the Trenches and the Stacks. IEEE Trans. Visualization and Computer Graphics (Proc. InfoVis) 18(12), 2431-2440 (2012)

37. Simões, D., Antunes, P., Cranefield, J.: Enriching Knowledge in Business Process Modelling: A Storytelling Approach, pp. 241-267. Springer Berlin Heidelberg, Berlin, Heidelberg (2016)

38. Smirnov, S., Weidlich, M., Mendling, J., Weske, M.: Action patterns in business process models. Comput. Ind. 63(2), 98-111 (2012) 
39. Stefan, L.: Virtual worlds in online education and training-an evaluation report. In: The International Scientific Conference eLearning and Software for Education. vol. 2, p. 453. " Carol I" National Defence University (2016)

40. Thom, L., Reichert, M., Iochpe, C.: Activity patterns in process-aware information systems: basic concepts and empirical evidence. Int. J. Bus. Process Integr. Manag. 4(2), 93-110 (2009)

41. Verginadis, Y., Papageorgiou, N., Apostolou, D., Mentzas, G.: A review of patterns in collaborative work. In: Proc. 16th ACM Int. Conf. Support. Gr. Work - Gr. '10. p. $283(2010)$ 